cells or their processes than mere shunting of excitation along certain channels. Inhibition, facilitation and after-discharge may be expected to occur in the sensory, just as they do in the reflex, pathway.

Until recently, it was necessary to rely mainly on subjective human experience in work on the physiology of the senses. Now, as a result of improved electro-physiological methods introduced by Adrian, it is possible to make objective records of events in single units at various levels in the ascending sensory pathway. Such studies not only provide a valuable check on what can otherwise be only rather indirectly inferred, but also give definite information about the anatomical site at which modification of messages occurs. There is still much scope for further advance of knowledge by both subjective and objective methods.

In skin, ear and eye, it is certain that there is considerable overlap in tho area of distribution of individual afferent nerve fibres. This has sometimes been thought to raise theoretical difficulties about the neurological basis of localization of stimuli. It is argued that thcse difficulties are largely illusory and that overlap may actually facilitate accurate identification of the site of stimulation.

The number of receptors is commonly much greater than the number of nerve fibres ascending to the sensorium. This forms the basis for the areal facilitation or summation which is so obvious a feature of natural stimulation of skin and retina. It also, however, provides opportunity for activity in one pathway to inhibit simultaneous activity in neighbouring pathways. There is evidence that this occurs in cutaneous, visual and auditory relay stations.

More puzzling is the multiplication of pathways for which, after preliminary convergence, there is good anatomical evidence in the senses of smell, vision and hearing. Although the sensorium, as analyser, clearly cannot manufacture detail out of material which is undetailed at lower levels, speculative suggestions are made about the possible avoidance of blurring which may result from such divergence.

Finally, the pathways from the two great paired sense-organs of sight and hearing are compared and contrasted. Physiological evidence indicates that in the former there is almost no confluence of the twin pathways from the two eyes even at the highest levels. In the latter, summation oceurs to such an extent that a sound heard with both ears has the same apparent loudness as one of double its physical intensity heard with a single ear.

\section{THE EFFECTIVE USE OF MAN-POWER}

$T^{N}$ his presidential address to Section J (Psychology), $1 \mathrm{Mr}$. Alec Rodger discusses the effective use of man-power. Ho spealss as an occupational psychologist, as a scientist and technologist concerned with the discovery and use of knowledge about people as workers of every kind and level. The knowledge the occupational psychologist is specially interested in is Innowledge about determinants of behaviour conveniently regarded as $(a)$ individual and internal, but $(b)$ 'left over' when the physiologist has done all the explaining he can manage. It is useful to call these, broadly, capacities and inclinations. The psychologist's task in his occupational specialization is to put our thinking about them on a sound theoretical basis and to bring it to bear, in a skilful fashion, on the problem of "fitting the man to the job' (through improvements in methods of vocational guidance; personnel selection; and occupational training) and the complementary problem of 'fitting the job to the man' (through improvements in methods and organization of work; equipment design; and working conditions of diverse kinds).

Before reviewing urgent tasks in these fields of interest, Mr. Rodger stresses the importance of recognizing their essential unity. It is unfortunate, he says, that psychologists dealing with one type of problem sometimes display little appreciation of thoroughly relevant work being done by their colleagues. For example, investigators concerned mainly with fitting the job to the man are inclined to assume that all mon are equal, or nearly so, in their capacities. They are therefore apt to overlook individual differences found to be crucial by investigators concerned chiefly with fitting the man to the job. This leads to misjudgment of the importance of the nature and size of the population samples used in their investigations, and to unwise expenditure of precious research funds on projects too narrowly conceived.

In the field of vocational guidance, where planning for the effective use of man-power should begin, the most pressing need is for long-term studies designed to reveal, by the application of appropriate criteria, the strong and weak points of currently used concepts and methods. On such studies will depend the solution of many major problems, including the most fundamental of all, that of classifying occupations for vocational guidance purposes. What is particu. larly required is a series of integrated studies of the differentiating capacities and inclinations of successes and relative failures in a variety of occupations. This notion is equally applicable to the study of certain personnel selection problems, including some arising in the management field. In the field of occupational training, consideration of individual differences in capacity and inclination may well lead to a radical overhaul of existing arrangements in Britain, not least of the apprenticeship system, which is archaic and wasteful.

Mr. Rodger, outlining some of the tasks awaiting the occupational psychologist in the field of methods and organization of work-the field of 'work-study'suggests that the nature and extent of the arbitrary judgments involved in time-study urgently require investigation. Until we know more about the answers to certain questions that arise here, we shall be entitled to wonder whether a good deal of time-study is not a piece of mumbo-jumbo developed-by agreement between managernent and workers-to provide an apparently rational basis for the payment of wages the amount of which has already been settled by quite other means. 'Touching on problems of equipment design, Mr. Rodger thinks it is time we began to take serious account of the fact that automation tends to produce a proportionately higher demand for skilled than for unskilled workers. He concludes by arguing that in the study of all the main factors to be considered in the shaping of wagedifferentials -skill, effort, responsibility, dirt and danger, to use Mr. Hugh Gaitskell's list - the occupational psychologist should have a contribution to make; for all these demand the investigation of problems of capacity and inclination, which are the occupational psychologist's meat and drink. 